\title{
Predictors of viral suppression and rebound among HIV-positive men who have sex with men in a large multi-site Canadian cohort
}

Zachary Tanner ${ }^{1}$, Nathan Lachowsky ${ }^{1,2,3}$, Erin Ding ${ }^{1}$, Hasina Samji ${ }^{1}$, Mark Hull ${ }^{1,4}$, Angela Cescon ${ }^{5}$, Sophie Patterson ${ }^{1,6}$, Jason Chia ${ }^{1}$, Alia Leslie ${ }^{1}$, Janet Raboud ${ }^{7,8}$, Mona Loutfy ${ }^{7,9,10,11}$, Curtis Cooper ${ }^{12}$, Marina Klein ${ }^{13,14}$, Nima Machouf ${ }^{15}$, Christos Tsoukas ${ }^{13}$, Julio Montaner ${ }^{1,4}$, and Robert S. Hogg $1,6,16^{*}$ for the Canadian Observation Cohort (CANOC) Collaboration

\begin{abstract}
Background: Gay, bisexual and other men who have sex with men (MSM) are disproportionately affected by HIV in Canada. Combination antiretroviral therapy has been shown to dramatically decrease progression to AIDS, premature death and HIV transmission. However, there are no comprehensive data regarding combination antiretroviral therapy outcomes among this population. We sought to identify socio-demographic and clinical correlates of viral suppression and rebound.

Methods: Our analysis included MSM participants in the Canadian Observational Cohort, a multi-site cohort of HIV-positive adults from Canada's three most populous provinces, aged $\geq 18$ years who first initiated combination antiretroviral therapy between 2000 and 2011. We used accelerated failure time models to identify factors predicting time to suppression ( 2 measures $<50$ copies $/ \mathrm{mL} \geq 30$ days apart) and subsequent rebound ( 2 measures $>200$ copies $/ \mathrm{mL} \geq 30$ days apart).
\end{abstract}

Results: Of 2,858 participants, 2,448 (86 \%) achieved viral suppression in a median time of 5 months (Q1-Q3: 3-7 months). Viral suppression was significantly associated with later calendar year of antiretroviral therapy initiation, no history of injection drug use, lower baseline viral load, being on an initial regimen consisting of non-nucleoside reverse-transcriptase inhibitors, and older age. Among those who suppressed, 295 (12\%) experienced viral rebound. This was associated with earlier calendar year of antiretroviral therapy initiation, injection drug use history, younger age, higher baseline CD4 cell count, and living in British Columbia.

Conclusions: Further strategies are required to optimize combination antiretroviral therapy outcomes in men who have sex with men in Canada, specifically targeting younger MSM and those with a history of injection drug use.

Keywords: Canada, HIV, MSM, Viral load, Suppression, Rebound

\footnotetext{
*Correspondence: robert_hogg@sfu.ca; bobhogg@cfenet.ubc.ca

${ }^{1}$ BC Centre for Excellence in HIV/AIDS, Vancouver, Canada

${ }^{6}$ Faculty of Health Sciences, Simon Fraser University, Vancouver, Canada

Full list of author information is available at the end of the article
} 


\section{Background}

Gay, bisexual and other men who have sex with men (MSM) have the highest prevalence of HIV in Canada [1]. Between 1985 and 2011, $54.7 \%$ of diagnosed HIV cases with known exposure status in Canada were attributable to MSM $(n=69,856)$, even though self-identified MSM comprise only an estimated $2.1 \%$ of the Canadian population $[1,2]$. In the first two decades of the epidemic, this disproportionate burden was characterized by premature mortality across MSM communities [3], with the estimated life expectancy of gay men in some urban environments being 8 to 20 years less than that of the general male population [4]. Since the implementation of combination antiretroviral therapy (cART), people living with HIV/AIDS (PHAs) have experienced significant improvements in health outcomes and can now achieve life expectancy near that of the general population [5-7]. High levels of adherence to cART, usually defined as taking $>95 \%$ of prescribed medication [8], usually results in full suppression of HIV-1-RNA levels in plasma, markedly improving health outcomes and similarly reducing the risk of HIV transmission [9]. Adherent patients generally achieve viral suppression between 8 and 24 weeks after initiating treatment [10].

Despite the proven clinical benefits of cART, Canadian MSM continue to experience a sustained rate of new HIV infections compared with the general population [1, 11]. A myriad of factors, including the heightened risk of infection via anal sex compared with vaginal sex [12]; behavioural factors, such as condomless anal intercourse and substance use [13]; and social factors, including homophobia, stigma, and social exclusion [11, 12, 14] have been advanced to explain these high rates of new infections. Additionally, structural barriers such as criminalization of HIV exposure [15], insufficient access to culturally appropriate health services and distrust of available health care providers [16-18], may deter some MSM from seeking HIV testing and treatment, as well as negatively impact retention rates. Continuation of treatment is crucial for long-term clinical success and prevention of viral rebound [19]. Failure to remain virally suppressed increases the risk of poor health outcomes, such as HIV drug resistance, progression to AIDS, premature death, and HIV transmission [20, 21].

While risk factors for HIV seroconversion among MSM have been largely explored, there is a sizable research gap regarding modern-day cART treatment responses. To date, there has not been an analysis of the clinical and social circumstances associated with virologic outcomes among MSM in Canada. The Public Health Agency of Canada has specifically identified this knowledge gap [1]. Furthermore, viral suppression is a principal component of the new UN 90-90-90 Target (i.e., to achieve $90 \%$ of PHA diagnosed globally, $90 \%$ of them on treatment, $90 \%$ of them on cART virally suppressed by 2020) [22]. This ambitious plan to end AIDS as a global pandemic provides a timely and pertinent framework for assessing where Canadian MSM on cART stand with regard to this target. The purpose of this study was to identify socio-demographic and clinical correlates of treatment response among MSM in Canada, as measured by viral suppression and subsequent virologic rebound. This will help inform cART retention strategies for MSM living with HIV.

\section{Methods \\ Study population}

The Canadian Observational Cohort (CANOC) collaboration is an observational cohort study of antiretroviralnaïve HIV-positive individuals initiating cART after 1 January 2000 [23]. This multi-site study is comprised of eight cohorts located in BC, Quebec, and Ontario. Almost half of the estimated 20,500 HIV-positive individuals on CART in these three provinces are represented within CANOC [24]. Patient eligibility criteria for inclusion in CANOC are: documented HIV infection, residence in Canada, aged 18 years or older, initiation of a first antiretroviral regimen comprised of at least three individual agents, and at least one measurement of HIV plasma viral load and CD4 T-cell count within one year of initiating cART. Patient selection and data extraction are performed locally at the data centres of the participating cohort sites. Demographic, laboratory, and clinical data from each cohort are then pooled and analysed at the Data Coordinating Centre in Vancouver, BC. For this analysis, we focused exclusively on males, excluding men with missing or unknown data regarding MSM status. We also excluded individuals who did not have at least two viral load measurements within one year after initiating cART, as well as those with less than one year of follow-up. The date of administrative censoring for this analysis was 31 December 2012.

The human subjects activities of CANOC were approved by the Simon Fraser University Research Ethics Board, the University of British Columbia Research Ethics Board and the following local institutional review boards of the participating cohorts: Providence Health Care Research Institute Office of Research Services, The Ottawa Hospital Research Ethics Board, University Health Network (UHN) Research Ethics Board, Véritas Institutional Review Board (IRB), Biomedical C (BMC) Research Ethics Board of the McGill University Heath Centre (MUHC), University of Toronto HIV Research Ethics Board (HIV REB), and Women's College Hospital Research Ethics Board.

Local cohort studies have obtained written consent except for the following: HAART Observational Medical Evaluation and Research (IRB approves the retrospective 
use of anonymous administrative data without requiring consent; an information sheet for participants is provided in lieu of a consent form); Ottawa Hospital Cohort (IRB approves the anonymous use of data retrospectively abstracted from clinical care databases without requiring consent); UHN (REB approves the anonymous use of data retrospectively abstracted from clinical care databases without requiring consent); MUHC (IRB approves the anonymous use of data retrospectively abstracted from clinical care databases without requiring consent; patients sign a general waiver on opening a medical chart at the hospital but no specific study related consent); Maple Leaf Medical Clinic (REB has approved the anonymous use of data retrospectively abstracted from clinical care databases without requiring consent); and Effective Anti-Retroviral Therapy cohort (REB approves the anonymous use of data retrospectively abstracted from clinical care databases without requiring consent; patients sign a general waiver on opening a medical chart at the hospital but no specific study related consent).

Further details on the collaborating cohorts and general CANOC structure are available [23].

\section{Outcomes}

Viral suppression after cART initiation was defined as the time to the first of at least two consecutive plasma HIV RNA measurements below 50 copies $/ \mathrm{mL}$, at least 30 days apart in the first year of treatment. We defined suppression within one year to focus on more timely virologic control [25]. Viral rebound was only measured among MSM who achieved viral suppression within the first year of treatment. Rebound was defined as the time to the first of at least two consecutive VL measures above 200 copies $/ \mathrm{mL}$, at least 30 days apart.

\section{Statistical methods}

Demographic and clinical characteristics at treatment initiation (baseline) were summarized using frequencies and proportions for categorical variables and medians and interquartile ranges (Q1-Q3) for continuous variables. Demographic and clinical characteristics of participants who achieved viral suppression within one year or did not achieve viral suppression within a year were compared using Chi-square tests for categorical variables and Wilcoxon Rank Sum tests for continuous variables.

Univariate accelerated failure time models with interval censoring were used to explore the association between covariates and each of the two outcomes. Covariates of interest included province of residence, race/ethnicity, age, baseline CD4 cell count, baseline viral load, history of injection drug use (IDU), baseline diagnosis of an AIDS-defining illness (ADI), era of cART initiation (i.e., 2000-2003, 2004-2007, 2008-2012), and third ARV class (i.e., NNRTI, boosted PI, unboosted PI, other). Calendar time of reaching viral suppression was also explored as a covariate in the rebound analysis because of its potential influence on subsequent rebound [26]. An exploratory model selection process based on Akaike Information Criterion (AIC), type III $p$-values, and a priori information was pursued to select variables for the multivariable accelerated failure time models examining time to viral suppression and rebound. The time origins were the first antiretroviral start date and the date of the first of two consecutive viral load measurements below 50 copies $/ \mathrm{mL}$ and above 200 copies $/ \mathrm{mL}$, for the suppression and rebound models, respectively. The multivariable models were fitted to an exponential distribution. All analyses were performed using SAS statistical software, version 9.3 (SAS Institute, Cary, NC).

\section{Results}

Baseline demographic and clinical characteristics of the study participants are listed in Table 1. Drawing on CANOC data from 2000 to 2011, 3,375 male participants were identified as MSM. 214 of these participants did not have at least two viral load measurements within one year after initiating cART, and another 303 participants had less than one year of follow-up. These participants were excluded from analysis, leaving a total of 2,858 men who met the eligibility criteria. By province, $30 \%$ of participants were from BC, $37 \%$ were from Ontario, and $34 \%$ were from Quebec. The median followup time was 5.0 years (Q1-Q3: 3.0-8.1 years). There were $192(7 \%)$ participants lost to follow-up (defined as no contact for $18+$ months), and $122(4 \%)$ died during follow-up. The median age of all participants was 40 years (Q1-Q3: 34-46 years). Among 1,441 participants with available ethnicity data, 1,320 (92\%) identified as White, 51 (4\%) as Black, and 70 (5\%) as Aboriginal. The median baseline CD4 count was 230 cells $/ \mathrm{mm}^{3}$ (Q1-Q3: $130-321$ cells $/ \mathrm{mm}^{3}$ ) and the median baseline viral load was $4.96 \log _{10}$ copies/mL (Q1-Q3 4.51-5.00 $\log _{10}$ copies $/ \mathrm{mL}$ ). Of the 2,744 participants with available hepatitis C (HCV) testing data, 331 (12\%) were seropositive. Additionally, 247 (9\%) participants had a history of IDU at the time of HIV diagnosis. At baseline, 459 (16\%) participants had been diagnosed with an ADI at or prior to CART initiation. The median rate of viral load testing was 4 tests per year (Q1-Q3: $3-5$ tests).

Table 2 highlights characteristics associated with MSM achieving at least two consecutive plasma HIV RNA measurements below 50 copies $/ \mathrm{mL}$, at least 30 days apart in the first year of treatment. At noted here, 2,448 (86 \%) MSM participants achieved viral suppression within 12 months of cART initiation. The median time to suppression was 5 months (Q1-Q3: 3-7 months). Of 
Table 1 Characteristics of MSM study participants at enrolment into CANOC $(n=2858)$

\begin{tabular}{|c|c|}
\hline Characteristic & Total (\%) \\
\hline \multicolumn{2}{|l|}{ Province } \\
\hline British Columbia & $854(30)$ \\
\hline Ontario & $1045(37)$ \\
\hline Quebec & $959(34)$ \\
\hline Age (years) & $40(34-46)$ \\
\hline \multicolumn{2}{|l|}{ Ethnicity } \\
\hline Caucasian & $1320(46)$ \\
\hline Black & $51(2)$ \\
\hline Aboriginal & $70(2)$ \\
\hline Other & $371(13)$ \\
\hline Unknown & $1046(37)$ \\
\hline \multicolumn{2}{|l|}{ History of IDU } \\
\hline No & $2555(89)$ \\
\hline Yes & $247(9)$ \\
\hline Unknown & $56(2)$ \\
\hline \multicolumn{2}{|l|}{ Hepatitis C status } \\
\hline No & $2413(84)$ \\
\hline Yes & $331(12)$ \\
\hline Unknown & $114(4)$ \\
\hline \multicolumn{2}{|l|}{ Era of CART initiation } \\
\hline $2000-2003$ & $729(26)$ \\
\hline $2004-2007$ & $931(33)$ \\
\hline 2008-2012 & $1198(42)$ \\
\hline \multicolumn{2}{|c|}{ Number of viral load tests per year } \\
\hline Less than 3 & $583(20)$ \\
\hline $3-4$ & $1590(56)$ \\
\hline $5-6$ & $360(13)$ \\
\hline More than 6 & $325(11)$ \\
\hline \multicolumn{2}{|l|}{ Initial 3rd ARV class } \\
\hline NNRTI & $1277(45)$ \\
\hline Unboosted PI & $128(4)$ \\
\hline Boosted PI & $1239(43)$ \\
\hline Other & $214(7)$ \\
\hline \multicolumn{2}{|l|}{ Initial 3rd ARV } \\
\hline Nevirapine & $252(9)$ \\
\hline Efavirenz & $1033(36)$ \\
\hline Lopinavir & $424(15)$ \\
\hline Atazanavir & $578(20)$ \\
\hline Other & $571(20)$ \\
\hline \multicolumn{2}{|l|}{ NRTI combination } \\
\hline Tenofovir/emtricitabine & $1217(43)$ \\
\hline Zidovudine/lamivudine & $594(21)$ \\
\hline Tenofovir/lamivudine & $207(7)$ \\
\hline
\end{tabular}

Table 1 Characteristics of MSM study participants at enrolment into CANOC $(n=2858)$ (Continued)

\begin{tabular}{|c|c|}
\hline Abacavir/lamivudine & $468(16)$ \\
\hline Stavudine/lamivudine & $212(7)$ \\
\hline Other & $160(6)$ \\
\hline \multicolumn{2}{|l|}{ AIDS-defining illness } \\
\hline No & $2284(80)$ \\
\hline Yes & $459(16)$ \\
\hline Unknown & $115(4)$ \\
\hline Viral load (log $\log _{10}$ copies/mL) & $4.96(4.51-5.00)$ \\
\hline CD4 count (cells/uL) & $230(130-321)$ \\
\hline
\end{tabular}

these 2,448 individuals, 295 (12\%) experienced a subsequent rebound above 200 HIV RNA copies/mL.

In bivariate analysis, time to viral suppression was significantly associated with IDU history $(p<0.001)$, calendar year of cART initiation $(p<0.001)$, initial composition of ARV regimen $(p<0.001)$, baseline viral load $(p<0.001)$, baseline CD4 count $(p=0.001)$, HCV co-infection $(p=0.001)$, age $(p=0.002)$, ethnicity $(p=0.002)$, having an ADI at baseline $(p=0.006)$, and province of residence $(p=0.011)$.

Tables 3 and 4 present the univariate and multivariable results of the accelerated failure time suppression and rebound models. In adjusted multivariable analysis, MSM who experienced viral suppression within one year of treatment initiation were more likely to have initiated cART from 2004 to 2007 [adjusted hazard ratio (aHR) 1.26, $95 \%$ confidence interval (CI) 1.11-1.42] and 2008-2012 [aHR 1.32, 95 \% CI 1.17-1.48] compared with 2000-2003, and to be older [aHR 1.08 per decade, $95 \%$ CI 1.03-1.13]. MSM who achieved suppressed viral loads were less likely to have an IDU history [aHR 0.71, $95 \%$ CI 0.60-0.85], higher baseline viral load [aHR 0.73 per $\log 10$ copies $/ \mathrm{mL}, 95 \%$ CI $0.66-0.80]$, and an unboosted PI [aHR 0.60, $95 \%$ CI $0.48-0.76$ ] or boosted PI [aHR 0.81, $95 \%$ CI 0.74-0.90] containing cART regimen (Table 3). The multivariable accelerated failure time model for viral rebound found that MSM who experienced a viral rebound were more likely to be younger [aHR 0.70 per decade, $95 \%$ CI $0.62-0.80$ ], to have an IDU history [aHR 2.52, $95 \%$ CI 1.82-3.50], a higher CD4 cell count at baseline [aHR 1.13 per 100 cells $/ \mathrm{mm}^{3}$, $95 \%$ CI 1.05-1.22], and less likely to have initiated cART from 2004 to 2007 [aHR 0.69, $95 \%$ CI 0.53-0.91] or 2008-2012 [aHR 0.43, $95 \%$ CI 0.30-0.61], and to be living in Ontario [aHR 0.50, $95 \%$ CI 0.38-0.67] or Quebec [aHR 0.51, $95 \%$ CI 0.38-0.69] (Table 4). 
Table 2 Characteristics associated with MSM achieving viral suppression in the first year of treatment

\begin{tabular}{|c|c|c|c|}
\hline \multirow[t]{2}{*}{ Characteristic } & \multicolumn{3}{|c|}{ Viral Suppression , n (\%) } \\
\hline & No $(n=410)$ & Yes $(n=2448)$ & $P$-value \\
\hline \multicolumn{4}{|l|}{ Province } \\
\hline British Columbia & $140(34)$ & $714(29)$ & \multirow[t]{3}{*}{0.011} \\
\hline Ontario & $158(39)$ & $887(36)$ & \\
\hline Quebec & $112(27)$ & $847(35)$ & \\
\hline Age (years) & $38(33-44)$ & $40(34-46)$ & 0.002 \\
\hline \multicolumn{4}{|l|}{ Ethnicity } \\
\hline Caucasian & $216(53)$ & $1104(45)$ & \multirow[t]{5}{*}{0.002} \\
\hline Black & $8(2)$ & $43(2)$ & \\
\hline Aboriginal & $17(4)$ & $53(2)$ & \\
\hline Other & $40(10)$ & $331(14)$ & \\
\hline Unknown & $129(31)$ & $917(37)$ & \\
\hline \multicolumn{4}{|l|}{ History of IDU } \\
\hline No & $336(82)$ & $2219(91)$ & \multirow[t]{3}{*}{$<0.001$} \\
\hline Yes & $60(15)$ & $187(8)$ & \\
\hline Unknown & $14(3)$ & $42(2)$ & \\
\hline \multicolumn{4}{|l|}{ Hepatitis C status } \\
\hline No & $321(78)$ & $2092(85)$ & \multirow[t]{3}{*}{0.001} \\
\hline Yes & $68(17)$ & $263(11)$ & \\
\hline Unknown & $21(5)$ & $93(4)$ & \\
\hline \multicolumn{4}{|l|}{ Era of CART initiation } \\
\hline 2000-2003 & $152(37)$ & $577(24)$ & \multirow[t]{3}{*}{$<0.001$} \\
\hline 2004-2007 & $127(31)$ & $804(33)$ & \\
\hline 2008-2012 & $131(32)$ & $1067(44)$ & \\
\hline \multicolumn{4}{|c|}{ Number of viral load tests per year } \\
\hline Less than 3 & $115(28)$ & $468(19)$ & \multirow[t]{4}{*}{$<0.001$} \\
\hline $3-4$ & $188(46)$ & $1402(57)$ & \\
\hline $5-6$ & $48(12)$ & $312(13)$ & \\
\hline More than 6 & $59(14)$ & $266(11)$ & \\
\hline \multicolumn{4}{|l|}{ Initial 3rd ARV class } \\
\hline NNRTI & $140(34)$ & $1137(46)$ & \multirow[t]{4}{*}{$<0.001$} \\
\hline Unboosted PI & $39(10)$ & $89(4)$ & \\
\hline Boosted PI & $194(47)$ & $1045(43)$ & \\
\hline Other & $37(9)$ & $177(7)$ & \\
\hline \multicolumn{4}{|l|}{ Initial 3rd ARV } \\
\hline Nevirapine & $41(10)$ & $211(9)$ & \multirow[t]{5}{*}{$<0.001$} \\
\hline Efavirenz & $105(26)$ & $928(38)$ & \\
\hline Lopinavir & $73(18)$ & $351(14)$ & \\
\hline Atazanavir & $79(19)$ & $499(20)$ & \\
\hline Other & $112(27)$ & 459 (19) & \\
\hline
\end{tabular}

Table 2 Characteristics associated with MSM achieving viral suppression in the first year of treatment (Continued)

\begin{tabular}{llll}
\hline NRTI combination & & & \\
Tenofovir/emtricitabine & $134(33)$ & $1083(44)$ & $<0.001$ \\
Zidovudine/lamivudine & $114(28)$ & $480(20)$ & \\
Tenofovir/lamivudine & $27(7)$ & $180(7)$ & \\
Abacavir/lamivudine & $58(14)$ & $410(17)$ & \\
Stavudine/lamivudine & $43(10)$ & $169(7)$ & \\
Other & $34(8)$ & $126(5)$ & \\
AIDS-defining illness & & & \\
No & $307(75)$ & $1977(81)$ & 0.006 \\
Yes & $88(21)$ & $371(15)$ & \\
Unknown & $15(4)$ & $100(4)$ & \\
Viral load (log 10 copies/mL) & $5.00(4.75-5.00)$ & $4.93(4.48-5.00)$ & $<0.001$ \\
CD4 count (cells/uL) & $190(100-310)$ & $231(134-327)$ & 0.001 \\
\hline
\end{tabular}

\section{Discussion}

Close to $90 \%$ of HIV-positive MSM receiving cART in CANOC achieved viral suppression within a median of 5 months of initiating treatment [27]. However, nearly one-in-eight HIV-positive MSM who achieved viral suppression on cART experienced viral rebound at some point following suppression during follow-up. This is the largest longitudinal, multi-provincial analysis of HIV treatment responses among MSM in Canada and demonstrates that MSM are close to UNAIDS' proposed targets that $90 \%$ of individuals on cART achieve viral suppression. This high rate suppression will ensure the long-term health of these men and limit new infections in this population.

The proportion of MSM achieving suppression in CANOC is similar to other studies from several international settings where the HIV burden is also predominantly concentrated among MSM. A large North American cohort study found that between 2001 and 2009 , the cumulative incidence of 1-year viral suppression was $84 \%$, observing that MSM participants had a higher likelihood of achieving suppression compared with other male participants [25]. Between 2010 and 2012 in Australia, it was estimated that the proportion of HIV-positive MSM on cART with undetectable viral loads increased from 85 to $90 \%$ [28]. Surveillance data from the United Kingdom (UK) suggests that $89 \%$ of MSM who initiated cART in 2009 were virally suppressed by 2010 [29]. Unfortunately these international viral suppression estimates for large HIV-positive MSM populations do not provide follow-up regarding episodes of subsequent rebound. But, in a large UK-based cohort study of previously antiretroviral naïve PHA on cART, of which approximately half were MSM, $11 \%$ experienced 
Table 3 Accelerated failure time models of factors associated with time to viral suppression among MSM

\begin{tabular}{|c|c|c|c|c|}
\hline & $\begin{array}{l}\text { Unadjusted hazard ratio } \\
\text { (95\% confidence interval) }\end{array}$ & $P$-value & $\begin{array}{l}\text { Adjusted hazard ratio } \\
\text { (95\% confidence interval) }\end{array}$ & $P$-value \\
\hline \multicolumn{5}{|l|}{ Province } \\
\hline British Columbia & 1.00 & 0.004 & 1.00 & 0.126 \\
\hline Ontario & $1.04(0.93-1.15)$ & & $0.98(0.88-1.10)$ & \\
\hline Quebec & $1.19(1.07-1.32)$ & & $1.09(0.98-1.22)$ & \\
\hline Baseline age (per 10 year increment) & $1.06(1.02-1.11)$ & 0.007 & $1.08(1.03-1.13)$ & 0.001 \\
\hline \multicolumn{5}{|l|}{ Ethnicity } \\
\hline Caucasian & 1.00 & 0.001 & & \\
\hline Black & $0.97(0.68-1.39)$ & & & \\
\hline Aboriginal & $0.75(0.55-1.01)$ & & & \\
\hline Other & $1.23(1.07-1.40)$ & & & \\
\hline Unknown & $1.13(1.03-1.25)$ & & & \\
\hline \multicolumn{5}{|l|}{ History of IDU } \\
\hline No & 1.00 & $<0.001$ & 1.00 & $<0.001$ \\
\hline Yes & $0.70(0.60-0.83)$ & & $0.71(0.60-0.85)$ & \\
\hline Unknown & $0.63(0.44-0.89)$ & & $0.71(0.50-1.02)$ & \\
\hline \multicolumn{5}{|l|}{ Era of CART initiation } \\
\hline $2000-03$ & 1.00 & $<0.001$ & 1.00 & $<0.001$ \\
\hline 2004-07 & $1.24(1.11-1.39)$ & & $1.26(1.11-1.42)$ & \\
\hline $2008-12$ & $1.42(1.27-1.58)$ & & $1.32(1.17-1.48)$ & \\
\hline \multicolumn{5}{|l|}{ Initial 3rd ARV class } \\
\hline NNRTI & 1.00 & $<0.001$ & 1.00 & $<0.001$ \\
\hline Unboosted PI & $0.53(0.42-0.67)$ & & $0.60(0.48-0.76)$ & \\
\hline Boosted PI & $0.82(0.75-0.90)$ & & $0.81(0.74-0.90)$ & \\
\hline Other & $0.81(0.67-0.97)$ & & $0.83(0.69-1.00)$ & \\
\hline \multicolumn{5}{|l|}{ Baseline AIDS-defining illness } \\
\hline No & 1.00 & 0.011 & & \\
\hline Yes & $0.84(0.74-0.94)$ & & & \\
\hline Unknown & $1.04(0.84-1.29)$ & & & \\
\hline Baseline viral load (per log10 copies/mL) & $0.73(0.66-0.80)$ & $<0.001$ & $0.73(0.66-0.80)$ & $<0.001$ \\
\hline Baseline CD4 count (per 100 cells $/ \mathrm{mm}^{3}$ ) & $1.04(1.02-1.07)$ & $<0.001$ & & \\
\hline
\end{tabular}

rebound [30], which is a similar proportion to MSM who experienced rebound in our analysis.

Consistent with previous research [31], our analysis found more recent calendar year of cART initiation to predict better treatment response within a large HIVpositive cohort. This may partially be explained by the simple fact that ARV regimens in more recent years have enhanced drug efficacy and reduced side effects, promoting more optimal treatment response. As part of our analysis, we also stratified antiretroviral regimens by era of cART initiation and found that in earlier calendar years, a significantly $(p<0.001)$ higher proportion of participants initiated treatment comprised of a Zidovudine and Lamivudine NRTI fixed combination (51, 23, and $1 \%$ of participants from 2000 to 2003, 2004 to 2007, and 2009 to 2012, respectively). In contrast, the bettertolerated and more effective [32] Tenofovir and Emtricitabine fixed-dose regimen was the predominant baseline NRTI combination in later calendar years $(0,25$, and $82 \%$ of participants initiating cART from 2000 to 2003, 2004 to 2007, and 2009 to 2012, respectively). Furthermore, in terms of ARV drug class, regimens comprised of NNRTIs were more effective than either boosted or unboosted PI-based for the treatment of patients with no previous exposure to antiretroviral therapy. This is congruous with a meta-analysis examining ARV regimens among HIV-infected patients with limited or no previous exposure to antiretroviral therapy [33]. NNRTIs were also most prevalent in more recent calendar years, with 49,33 , and $51 \%$ of participants initiating a regimen 
Table 4 Accelerated failure time models of factors associated with time to viral rebound among MSM who suppressed

\begin{tabular}{|c|c|c|c|c|}
\hline & $\begin{array}{l}\text { Unadjusted hazard ratio } \\
\text { (95\% confidence interval) }\end{array}$ & $P$-value & $\begin{array}{l}\text { Adjusted hazard ratio } \\
\text { (95\% confidence interval) }\end{array}$ & $P$-value \\
\hline \multicolumn{5}{|l|}{ Province } \\
\hline British Columbia & 1.00 & $<0.001$ & 1.00 & $<0.001$ \\
\hline Ontario & $0.54(0.42-0.71)$ & & $0.50(0.38-0.67)$ & \\
\hline Quebec & $0.48(0.36-0.64)$ & & $0.51(0.38-0.69)$ & \\
\hline Baseline age (per 10 year increment) & $0.75(0.66-0.86)$ & $<0.001$ & $0.70(0.62-0.80)$ & $<0.001$ \\
\hline \multicolumn{5}{|l|}{ Ethnicity } \\
\hline Caucasian & 1.00 & 0.008 & & \\
\hline Black & $1.35(0.60-3.06)$ & & & \\
\hline Aboriginal & $1.67(0.93-3.00)$ & & & \\
\hline Other & $0.98(0.70-1.38)$ & & & \\
\hline Unknown & $0.67(0.51-0.89)$ & & & \\
\hline \multicolumn{5}{|l|}{ History of IDU } \\
\hline No & 1.00 & $<0.001$ & 1.00 & $<0.001$ \\
\hline Yes & $2.67(1.96-3.64)$ & & $2.52(1.82-3.50)$ & \\
\hline Unknown & $2.02(1.04-3.93)$ & & $2.18(1.09-4.36)$ & \\
\hline \multicolumn{5}{|l|}{ Era of CART initiation } \\
\hline 2000-03 & 1.00 & $<0.001$ & 1.00 & $<0.001$ \\
\hline 2004-07 & $0.71(0.56-0.92)$ & & $0.69(0.53-0.91)$ & \\
\hline $2008-12$ & $0.49(0.35-0.69)$ & & $0.43(0.30-0.61)$ & \\
\hline \multicolumn{5}{|l|}{ Initial 3rd ARV class } \\
\hline NNRTI & 1.00 & 0.082 & 1.00 & 0.057 \\
\hline Unboosted PI & $1.60(0.99-2.59)$ & & $1.48(0.90-2.42)$ & \\
\hline Boosted PI & $1.16(0.91-1.49)$ & & $1.13(0.86-1.48)$ & \\
\hline Other & $1.53(1.01-2.31)$ & & $1.70(1.12-2.59)$ & \\
\hline \multicolumn{5}{|l|}{ Baseline AIDS-defining illness } \\
\hline No & 1.00 & & & \\
\hline Yes & $0.99(0.73-1.34)$ & & & \\
\hline Unknown & $1.00(0.58-1.72)$ & 0.999 & & \\
\hline Baseline viral load (per log10 copies/mL) & $1.11(0.85-1.45)$ & 0.454 & & \\
\hline Baseline CD4 count (per 100 cells $/ \mathrm{mm}^{3}$ ) & $1.05(0.97-1.13)$ & 0.227 & $1.13(1.05-1.22)$ & 0.001 \\
\hline Time to suppression (months) & $1.04(0.99-1.09)$ & 0.118 & $1.04(0.99-1.09)$ & 0.144 \\
\hline
\end{tabular}

comprised of NNRTIs from 2000 to 2003, 2004 to 2007, and 2009 to 2012, respectively. More frequent rebound episodes, especially in British Columbia and in earlier calendar years, may also reflect physician-recommended structured treatment interruptions, which were more common during earlier cART eras and in British Columbia [34].

The low median baseline CD4 cell count among participants $\left(230\right.$ cells $\left./ \mathrm{mm}^{3}\right)$ is concerning, although guidelines for the timing of cART initiation have changed significantly over the period of study. The median baseline CD4 cell count increased throughout the study timeline, likely in response to these updated guidelines. In 2000, the median baseline CD4 cell count among all participants was 183 cells $/ \mathrm{mm}^{3}$, whereas in 2011, this measure was 358 cells $/ \mathrm{mm}^{3}$. Although an improvement, other studies have demonstrated that PHA who initiate cART with CD4 cell measures below 350 cells $/ \mathrm{mm}^{3}$ are at higher risk of AIDS and death than individuals who begin treatment at higher CD4 thresholds [35-37]. Recurrent viral load testing among PHA who started cART with lower CD4 counts is crucial for informing changes in ARV regimens that are necessary for preventing treatment failure and adverse health outcomes.

Our finding that higher baseline CD4 cell count was a significant predictor of viral rebound was surprising $[38,39]$. It is possible that cART adherent MSM with high baseline CD4 cell counts retained comparatively 
better health throughout the study timeline, which may have influenced them to "take a break" from their medication [40, 41]. However, recent research set in the Canadian context has found no association between high CD4 counts $\left(\geq 500\right.$ cells $\left./ \mathrm{mm}^{3}\right)$ and lower rates of adherence [42]. Going forward, it is important to examine this issue more closely. Recommendations for initiating cART immediately, regardless of CD4 cell count, emerged after our period of study, first in 2013 for select populations [10], and in 2015 for all PHA $[37,43]$. As such, the proportion of PHA initiating cART at higher CD4 counts will increase in the future, providing an opportunity to obtain a better understanding of its predictive value regarding cART adherence.

This analysis discerned a few populations at risk of poorer virologic outcomes, including younger MSM and those with a history of injection drug use. Adverse treatment response was particularly evident in this latter group, who had 0.71 times the likelihood of achieving suppression, and over 2.5 times the chance of experiencing rebound. Their reduced probability of achieving and sustaining undetectable viral loads hinders UNAIDS suppression targets and has potential negative implications for future health outcomes, and on going HIV transmission. Younger MSM can face a wide array of challenges, including sexual identity issues, substance abuse, precarious employment, and housing instability [44]. Understandably, these conditions may complicate balancing a lifelong cART regimen and coming to terms with having a chronic and stigmatized disease. Health care providers with younger HIV-positive MSM patients should become more knowledgeable about local LGBTfocused hotlines, agencies, and media so that they can better connect them to these services, which may help improve HIV treatment self-efficacy and facilitate improved cART adherence [45]. Furthermore, HIV case management services should accommodate more flexible hours to promote continued engagement in care, as younger HIV-positive MSM are more likely to miss scheduled appointment times, and provide more flexible scheduling as this been has previously demonstrated to improve clinical care attendance and HIV treatment response among this population [46]. For improving treatment responses among MSM who also use injection drugs, more intensive case management and psychosocial support services have a strong record of improving retention in care among more vulnerable HIV-positive populations $[47,48]$. For example, incorporating harm reduction services such as supervised injection facilities into HIV care settings and increasing the availability of methadone maintenance therapy may also lead to more consistent viral load suppression among MSM-IDU [49, 50].

\section{Strengths and limitations}

Readers should be cautious when reviewing our findings even though our study was based on large group of MSM and 12-year follow-up period. Most notably, our study only included Canada's three largest provinces, Ontario, Quebec and British Columbia, however, we did include most MSM as currently $85 \%$ of PHAs in Canada live in these provinces [51]. The provincial differences in treatment response are likely explained by the fact that British Columbia includes the entire sample of CANOC-eligible individuals province-wide while data from Ontario and Québec included a selection of individuals from specialized HIV clinics (the majority being in urban centres). Men with missing or unknown MSM status $(n=2,073)$ were excluded from this analysis. Moreover, our results only pertain to MSM participants who had at least two viral load measurements within one year after initiating cART, as well as individuals with at least one year of follow-up. However, excluding this group from our analyses did not heavily bias our results, because male participants with unknown MSM status did not differ from the MSM sample significantly with regard to baseline CD4 cell count, achieving suppression, or experiencing rebound.

\section{Conclusions}

Our results show that over $80 \%$ of HIV-positive MSM with at least one year of follow-up achieved and maintained suppressed HIV viral levels. However, $12 \%$ of MSM who achieved viral suppression went on to experience viral rebound within the study period. To better realize the UNAIDS $90 \%$ suppression target, further strategies are required to optimize cART outcomes in MSM in Canada, specifically targeting younger MSM and those with a history of IDU.

\section{Appendix}

The CANOC Collaborative Research Centre includes: CANOC Principal Investigator: Robert Hogg (British Columbia Centre for Excellence in HIV/AIDS, Simon Fraser University) Site Principal Investigators: Ann N. Burchell (Ontario HIV Treatment Network, University of Toronto, OHTN Cohort Study [OCS]), Curtis Cooper (University of Ottawa, OCS), Deborah Kelly (Memorial University of Newfoundland), Marina Klein (Montreal Chest Institute Immunodeficiency Service Cohort, McGill University), Mona Loutfy (University of Toronto, Maple Leaf Medical Clinic, OCS), Nima Machouf (Clinique Medicale l'Actuel, Université de Montréal), Julio Montaner (British Columbia Centre for Excellence in HIV/AIDS, University of British Columbia), Janet Raboud (University of Toronto, University Health Network, OCS), Chris Tsoukas (McGill University), Stephen Sanche (University of Saskatchewan), Alexander Wong (University 
of Saskatchewan) Co-Principal Investigators: Tony Antoniou (St. Michael's Hospital, University of Toronto, Institute for Clinical Evaluative Sciences), Ahmed Bayoumi (St. Michael's Hospital, University of Toronto), Mark Hull (British Columbia Centre for Excellence in HIV/AIDS), Bohdan Nosyk (British Columbia Centre for Excellence in HIV/AIDS, Simon Fraser University) Co-Investigators: Angela Cescon (Northern Ontario School of Medicine), Michelle Cotterchio (Cancer Care Ontario, University of Toronto), Charlie Goldsmith (Simon Fraser University), Silvia Guillemi (British Columbia Centre for Excellence in HIV/AIDS, University of British Columbia), P. Richard Harrigan (British Columbia Centre for Excellence in HIV/ AIDS, University of British Columbia), Marianne Harris (St. Paul's Hospital), Sean Hosein (CATIE), Sharon Johnston (Bruyère Research Institute, University of Ottawa), Claire Kendall (Bruyère Research Institute, University of Ottawa), Clare Liddy (Bruyère Research Institute, University of Ottawa), Viviane Lima (British Columbia Centre for Excellence in HIV/AIDS, University of British Columbia), David Marsh (Northern Ontario School of Medicine), David Moore (British Columbia Centre for Excellence in HIV/ AIDS, University of British Columbia), Alexis Palmer (British Columbia Centre for Excellence in HIV/AIDS, Simon Fraser University), Sophie Patterson (British Columbia Centre for Excellence in HIV/AIDS, Simon Fraser University), Peter Phillips (British Columbia Centre for Excellence in HIV/AIDS, University of British Columbia), Anita Rachlis (University of Toronto, OCS), Sean B. Rourke (University of Toronto, OCS), Hasina Samji (British Columbia Centre for Excellence in HIV/AIDS), Marek Smieja (McMaster University), Benoit Trottier (Clinique Medicale l'Actuel, Université de Montréal), Mark Wainberg (McGill University, Lady Davis Institute for Medical Research), Sharon Walmsley (University Health Network, University of Toronto) Collaborators: Chris Archibald (Public Health Agency of Canada Centre for Communicable Diseases and Infection Control), Ken Clement (Canadian Aboriginal AIDS Network), Fred Crouzat (Maple Leaf Medical Clinic), Monique Doolittle-Romas (Canadian AIDS Society), Laurie Edmiston (Canadian Treatment Action Council), Sandra Gardner (OHTN, University of Toronto, OCS), Brian Huskins (Canadian Treatment Action Council), Jerry Lawless (University of Waterloo), Douglas Lee (University Health Network, University of Toronto, ICES), Renee Masching (Canadian Aboriginal AIDS Network), Stephen Tattle (Canadian Working Group on HIV \& Rehabilitation), Alireza Zahirieh (Sunnybrook Health Sciences Centre) Analysts and Staff: Claire Allen (Regina General Hospital), Stryker Calvez (SHARE), Guillaume Colley (British Columbia Centre for Excellence in HIV/AIDS), Jason Chia (British Columbia Centre for Excellence in HIV/AIDS), Daniel Corsi (The Ottawa Hospital Immunodeficiency
Clinic, Ottawa Hospital Research Institute), Louise Gilbert (Immune Deficiency Treatment Centre), Nada Gataric (British Columbia Centre for Excellence in HIV/AIDS), Alia Leslie (British Columbia Centre for Excellence in HIV/ AIDS), Lucia Light (OHTN), David Mackie (The Ottawa Hospital), Costas Pexos (McGill University), Susan Shurgold (British Columbia Centre for Excellence in HIV/ AIDS), Leah Szadkowski (University Health Network), Chrissi Galanakis (Clinique Médicale L'Actuel), Ina Sandler (Maple Leaf Medical Clinic), Benita Yip (British Columbia Centre for Excellence in HIV/AIDS), Jaime Younger (University Health Network), and Julia Zhu (British Columbia Centre for Excellence in HIV/AIDS).

\section{Abbreviations}

ADI: AIDS-defining illness; AHR: Adjusted hazard ratio; AIC: Akaike Information Criterion; AIDS: Acquired immune deficiency syndrome; ARV: Antiretroviral; BC: British Columbia; CANOC: Canadian Observational Cohort; CART: Combination antiretroviral therapy; Cl: Confidence interval; HCV: Hepatitis C; HIV: Human immunodeficiency virus; HR: Hazard ratio; IDU: Injection drug use; IRB: Institutional review board; LGBT: Lesbian, gay, bisexual and transgender; MSM: Men who have sex with men; MUHC: McGill University Health Centre; NNRTI: Nonnucleoside reverse transcriptase inhibitor; PHA: People living with HIV; PI: Protease inhibitor; REB: Research ethics board; RNA: Ribonucleic acid; UK: United Kingdom; UNAIDS: United Nations Programme on HIV/AIDS

\section{Acknowledgements}

We would like to thank all of the participants for allowing their information to be a part of the CANOC collaboration.

\section{Funding}

CANOC is funded by the Canadian Institutes of Health Research (CIHR) through a Centres Grant (Centres for HIV/AIDS Population Health and Health Services Research), two Operating Grants (HIV/AIDS Priority Announcement; Population and Public Health), and is also supported by the CIHR Canadian HIV Trials Network (CTN242). NJL is supported by a CANFAR/CTN

Postdoctoral Fellowship Award. AC is supported through a CANOC Centre Scholar Award. CC is supported through an Applied HIV Research Chair from the OHTN. MBK is supported by a Chercheur-Boursier Clinicien Senior Career Award from the Fonds de recherche en santé du Québec (FRSQ). MRL receives salary support from CIHR. JSGM is supported by an Avant-Garde Award from the National Institute on Drug Abuse, National Institutes of Health. SP is supported by a Study Abroad Studentship from the Leverhulme Trust. JR is supported through an OHTN Chair in Biostatistics. The funders had no role in study design, data collection and analysis, decision to publish, or preparation of the manuscript. The authors have no competing interests to declare.

\section{Availability of data and materials}

There are data sharing agreements in place that prohibit the authors from making the data set publicly available. Readers may contact Dr. Robert Hogg for further clarification.

\section{Authors' contributions \\ The author's contributions are as follows: ZT, HS, ED, and JC conceived of and designed the study. ED and JC performed all statistical analyses. All authors contributed to the interpretation of the data and reviewed the manuscript critically for important intellectual content. ZPT, NJL, and HS helped draft the manuscript. RSH advised on all aspects of the study. All authors read and approved the final manuscript.}

\section{Competing interests}

Conflict of Interest: MBK reports grants from Merck and ViiV Healthcare and personal fees for consultancy from ViiV Healthcare, Bristol-Meyers Squibb, and Gilead Sciences. NM has been a speaker for Bristol-Meyers Squibb, Merck, and ViiV Healthcare. JSGM is supported by the British Columbia Ministry of Health and by the US National Institutes of Health (R01DA036307), 
and he has received unrestricted funding, paid to his institution, from Abbvie, Bristol-Myers Squibb, Gilead Sciences, Janssen, Merck, and ViiV Healthcare. JR is a co-investigator on two projects with in-kind contributions from Merck and Gilead Sciences, outside the submitted work. All other authors declare that they have no competing interest.

\section{Ethics approval and consent to participate}

The human subjects activities of CANOC were approved by the Simon Fraser University Research Ethics Board, the University of British Columbia Research Ethics Board and the following local institutional review boards of the participating cohorts: Providence Health Care Research Institute Office of Research Services, The Ottawa Hospital Research Ethics Board, University Health Network (UHN) Research Ethics Board, Véritas Institutional Review Board (IRB), Biomedical C (BMC) Research Ethics Board of the McGill University Heath Centre (MUHC), University of Toronto HIV Research Ethics Board (HIV REB), and Women's College Hospital Research Ethics Board. Local cohort studies have obtained written consent except for the following: HAART Observational Medical Evaluation and Research (IRB approves the retrospective use of anonymous administrative data without requiring consent; an information sheet for participants is provided in lieu of a consent form); Ottawa Hospital Cohort (IRB approves the anonymous use of data retrospectively abstracted from clinical care databases without requiring consent); UHN (REB approves the anonymous use of data retrospectively abstracted from clinical care databases without requiring consent); MUHC (IRB approves the anonymous use of data retrospectively abstracted from clinical care databases without requiring consent; patients sign a general waiver on opening a medical chart at the hospital but no specific study related consent); Maple Leaf Medical Clinic (REB has approved the anonymous use of data retrospectively abstracted from clinical care databases without requiring consent); and Effective Anti-Retroviral Therapy cohort (REB approves the anonymous use of data retrospectively abstracted from clinical care databases without requiring consent; patients sign a general waiver on opening a medical chart at the hospital but no specific study related consent).

\section{Author details}

${ }^{1}$ BC Centre for Excellence in HIV/AIDS, Vancouver, Canada. ${ }^{2}$ School of Public Health \& Social Policy, University of Victoria, Victoria, Canada. ${ }^{3}$ Centre for Addiction Research British Columbia, University of Victoria, Victoria, Canada. ${ }^{4}$ Faculty of Medicine, University of British Columbia, Vancouver, Canada. ${ }^{5}$ Northern Ontario School of Medicine, Sudbury, Canada. ${ }^{6}$ Faculty of Health Sciences, Simon Fraser University, Vancouver, Canada. ${ }^{7}$ Dalla Lana School of Public Health, University of Toronto, Toronto, Canada. ${ }^{8}$ Toronto General Research Institute, University Health Network, Toronto, Canada. ${ }^{9}$ Faculty of Medicine, University of Toronto, Toronto, Canada. ${ }^{10}$ Maple Leaf Medical Clinic, Toronto, Canada. ${ }^{11}$ Women's College Research Institute, Women's College Hospital, Toronto, Canada. ${ }^{12}$ The Ottawa Hospital Research Institute, University of Ottawa, Ottawa, Canada. ${ }^{13}$ Faculty of Medicine, McGill University, Montreal, Canada. ${ }^{14}$ The Montreal Chest Institute, McGill University Health Centre, Montreal, Canada. ${ }^{15}$ Clinique Medicale I'Actuel, Montreal, Canada. ${ }^{16}$ Faculty of Health Sciences, Simon Fraser University, BLU 9512, 8888 University Drive, Burnaby, BC V5A 1S6, Canada.

\section{Received: 22 June 2016 Accepted: 12 October 2016} Published online: 21 October 2016

\section{References}

1. Public Health Agency of Canada. Population Specific HIV/AIDS Status Report: Gay, Bisexual, Two-spirit and other Men who have Sex with Men. 2013. p. 120171.

2. Statistics Canada. Canadian Community Health Survey, 2010 (data file). 2011. p. 3226.

3. Strathdee SA, Martindale SL, Cornelisse PG, Miller ML, Craib KJ, Schechter MT, O'Shaughnessy MV, Hogg RS. HIV infection and risk behaviours among young gay and bisexual men in Vancouver. CMAJ. 2000;162(1):21-5.

4. Hogg RS, Strathdee SA, Craib KJ, O'Shaughnessy MV, Montaner JS, Schechter MT. Modelling the impact of HIV disease on mortality in gay and bisexual men. Int J Epidemiol. 1997;26(3):657-61.

5. Hogg RS, Heath KV, Yip B, Craib KJ, O'Shaughnessy MV, Schechter MT, Montaner JS. Improved survival among HIV-infected individuals following initiation of antiretroviral therapy. JAMA. 1998;279(6):450-4.
6. Lima VD, Hogg RS, Harrigan PR, Moore D, Yip B, Wood E, Montaner JS. Continued improvement in survival among HIV-infected individuals with newer forms of highly active antiretroviral therapy. AIDS. 2007;21(6):685-92.

7. Samji H, Cescon A, Hogg RS, Modur SP, Althoff KN, Buchacz K, Burchell AN, Cohen M, Gebo KA, Gill MJ, Justice A, Kirk G, Klein MB, Korthuis PT, Martin J, Napravnik S, Rourke SB, Sterling TR, Silverberg MJ, Deeks S, Jacobson LP, Bosch RJ, Kitahata MM, Goedert JJ, Moore R, Gange SJ, North American AIDS Cohort Collaboration on Research and Design (NA-ACCORD) of leDEA. Closing the gap: increases in life expectancy among treated HIV-positive individuals in the United States and Canada. PLoS One. 2013;8(12):e81355.

8. O'Neil CR, Palmer AK, Coulter S, O'Brien N, Shen A, Zhang W, Montaner JSG, Hogg RS. Factors associated with antiretroviral medication adherence among HIV-positive adults accessing highly active antiretroviral therapy (HAART) in British Columbia, Canada. J Int Assoc Phys AIDS Care. 2012;11(2):134-41.

9. Montaner JS, Lima VD, Barrios R, Yip B, Wood E, Kerr T, Shannon K, Harrigan PR, Hogg RS, Daly P, Kendall P. Association of highly active antiretroviral therapy coverage, population viral load, and yearly new HIV diagnoses in British Columbia, Canada: A population-based study. Lancet. 2010;376:532-9.

10. Panel on Antiretroviral Guidelines for Adults and Adolescents: Guidelines for the use of antiretroviral agents in HIV-1-infected adults and adolescents. 2013.

11. British Columbia. Provincial Health Officer: HIV, Stigma and Society: Tackling a Complex Epidemic and Renewing HIV Prevention for Gay and Bisexual Men in British Columbia. Provincial Health Officer's 2010 Annual Report. 20142014

12. Jaffe HW, Valdiserri RO, De Cock KM. The reemerging HIV/AIDS epidemic in men who have sex with men. JAMA. 2007;298(20):2412-4.

13. Benzie AA, Bansi LK, Sabin CA, Walsh JC, Phillips AN, on behalf of the United Kingdom Collaborative HIV Cohort (UK CHIC). Increased duration of viral suppression is associated with lower failure rates regardless of previous treatment failure. AIDS. 2007;21:1423-30.

14. Jeffries WL, Marks G, Lauby J, Murrill C, Millett GA. Homophobia is associated with sexual behavior that increases risk of acquiring and transmitting HIV infection among black men who have sex with men. AIDS Behav. 2013;17(4):1442-53.

15. O'Byrne P, Bryan A, Woodyatt C. Nondisclosure prosecutions and HIV prevention: results from an Ottawa-based gay men's sex survey. J Assoc Nurses AIDS Care. 2013;24(1):81-7.

16. Nelson KM, Thiede H, Hawes SE, Golden MR, Hutcheson R, Carey JW, Kurth A, Jenkins RA. Why the wait? Delayed HIV diagnosis among men who have sex with men. J Urban Health. 2010;87(4):642-55.

17. Arnold EA, Rebchook GM, Kegeles SM. Triply cursed': Racism, homophobia and HIV-related stigma are barriers to regular HIV testing, treatment adherence and disclosure among young Black gay men. Cult Health Sex. 2014;16(6):710-22

18. O'Byrne P, MacPherson P, Ember A, Grayson MO, Bourgault A. Overview of a gay men's STI/HIV testing clinic in Ottawa: clinical operations and outcomes. Can J Public Health. 2014;105(5):389-94.

19. Raboud JM, Rae S, Woods R, Harris M, Montaner JS, INCAS and AVANTI Study Groups. Consecutive rebounds in plasma viral load are associated with virological failure at 52 weeks among HIV-infected patients. AIDS. 2002; 16(12):1627-32.

20. Castilla J, Del Romero J, Hernando V, Marincovich B, García S, Rodríguez C. Effectiveness of highly active antiretroviral therapy in reducing heterosexual transmission of HIV. J Acquir Immune Defic Syndr. 2005;40(1):96-101.

21. de Mendoza C, Soriano V, Pérez-Olmeda M, Rodés B, Casas E, GonzálezLahoz J. Different outcomes in patients achieving complete or partial viral load suppression on antiretroviral therapy. J Hum Virol. 1999;2(6):344-9.

22. UNAIDS. 90-90-90: An ambitious treatment target to help end the AIDS epidemic. 2014.

23. Palmer AK, Klein MB, Raboud J, Cooper C, Hosein S, Loutfy M, Machouf N, Montaner J, Rourke SB, Smieja M, Tsoukas C, Yip B, Milan D, Hogg RS, CANOC Collaboration. Cohort profile: the Canadian Observational Cohort collaboration. Int J Epidemiol. 2011;40(1):25-32.

24. Hogg RS, Heath K, Lima VD, Nosyk B, Kanters S, Wood E, Kerr T, Montaner JS. Disparities in the burden of HIV/AIDS in Canada. PLoS One. 2012;7(11):e47260

25. Hanna DB, Buchacz K, Gebo KA, Hessol NA, Horberg MA, Jacobson LP, Kirk GD, Kitahata MM, Korthuis PT, Moore RD, Napravnik SP P, Silverberg MJ, Sterling TR, Willig JH, Lau B, Althoff KN, Crane HM, Collier AC, Samji H, 
Thorne JE, Gill MJ, Klein MB, Martin JN, Rodriguez B, Rourke SB, Gange SJ, North American AIDS Cohort Collaboration on Research and Design (NA-ACCORD) of the International Epidemiologic Databases to Evaluate AIDS. Trends and disparities in antiretroviral therapy initiation and virologic suppression among newly treatment-eligible HIV-infected individuals in North America, 2001-2009. Clin Infect Dis. 2013;56(8):1174-82.

26. Jose S, Waters LI, Edwards S, Benn P, Sabin C, UK CHIC. The impact of baseline viral load $(\mathrm{VL})$ and time to viral suppression on treatment response to first-line combination antiretroviral therapy (CART). 14th European AIDS Conference. Brussels; 2013.

27. Canada's health care system. Health Canada. 2012. http://www.hc-sc.gc.ca/ hcs-sss/pubs/system-regime/2011-hcs-sss/index-eng.php.

28. de la Mata NL, Mao L, de WitB J, Smith D, Holt M, Prestage G, Wilson DP, Petoumenos K. Estimating antiretroviral treatment coverage rates and viral suppression rates for homosexual men in Australia. Sex Health. 2015;13 [Epub ahead of print].

29. Delpech V, Yin Z, Kall M, Brown A. The United Kingdom's National Health Service (NHS) provides excellent access to high quality HIV care: Results from a national cohort. 19th International AIDS Conference. Washington, D.C.; 2012

30. United Kingdom Collaborative HIV Cohort Study, Lee KJ, Dunn D, Gilson R, Porter K, Bansi L, Hill T, Phillips AN, Sabin CA, Schwenk A, Leen C, Delpech V, Anderson J, Gazzard B, Johnson M, Easterbrook P, Walsh J, Fisher M, Orkin C. Treatment switches after viral rebound in HIV-infected adults starting antiretroviral therapy: multicentre cohort study. AIDS. 2008;22(15):1943-50.

31. Sozio F, Soddu V, De Socio G, D'Alessandro M, Polilli E, Madeddu G, Bonfanti P, Mazzotta E, Vecchiet J, Mura MS, Quirino T, Manzoli L, Parruti G. Comparison of the efficacy at 48 weeks of first-line antiretroviral treatment for HIV infection in 1998 and 2006: A multicentric investigation. J Int AIDS Soc. 2008;11.

32. Gallant JE, DeJesus E, Arribas JR, Pozniak AL, Gazzard B, Campo RE, Lu B, McColl D, Chuck S, Enejosa J, Toole JJ, Cheng AK. Tenofovir DF, Emtricitabine, and Efavirenz vs. Zidovudine, Lamivudine, and Efavirenz for HIV. N Engl J Med. 2006;354(3):251-60.

33. Chou R, Fu R, Huffman LH, Korthuis PT. Initial highly-active antiretroviral therapy with a protease inhibitor versus a non-nucleoside reverse transcriptase inhibitor: discrepancies between direct and indirect meta-analyses. Lancet. 2006;368:1503-15.

34. Lori F, Lisziewicz J. Structured treatment interruptions for the management of HIV infection. JAMA. 2001;286(23):2981-7.

35. Sterne JA, May M, Costagliola D, de Wolf F, Phillips AN, Harris R, Funk MJ, Geskus RB, Gill J, Dabis F, Miró JM, Justice AC, Ledergerber B, Fätkenheuer G, Hogg RS, Monforte AD, Saag M, Smith C, Staszewski S, Egger M, Cole SR. When To Start Consortium: Timing of initiation of antiretroviral therapy in AIDS-free HIV-1-infected patients: a collaborative analysis of 18 HIV cohort studies. Lancet. 2009:373:1352-63.

36. Kitahata MM, Gange SJ, Abraham AG, Merriman B, Saag MS, Justice AC, Hogg RS, Deeks SG, Eron JJ, Brooks JT, Rourke SB, Gill MJ, Bosch RJ, Martin JN, Klein MB, Jacobson LP, Rodriguez B, Sterling TR, Kirk GD, Napravnik S, Rachlis AR, Calzavara LM, Horberg MA, Silverberg MJ, Gebo KA, Goedert JJ, Benson CA, Collier AC, Van Rompaey SE, Crane HM, McKaig RG, Lau B, Freeman AM, Moore RD, NA-ACCORD Investigators. Effect of early versus deferred antiretroviral therapy for HIV on survival. N Engl J Med. 2009; 360(18):1815-26

37. The INSIGHT START Study Group. Initiation of antiretroviral therapy in early asymptomatic HIV infection. N Engl J Med. 2015;373(9):795-807.

38. Street $\mathrm{E}$, Curtis H, Sabin CA, Monteiro EF, Johnson MA, British HIV Association (BHIVA) and BHIVA Audit and Standards Subcommittee. British HIV Association (BHIVA) national cohort outcomes audit of patients commencing antiretrovirals from naïve. HIV Med. 2009;10(6):337-42.

39. Samji H, Taha TE, Moore D, Burchell AN, Cescon A, Cooper C, Raboud JM, Klein MB, Loutfy MR, Machouf N, Tsoukas CM, Montaner JS, Hogg RS, Canadian Observational Cohort (CANOC) Collaboration. Predictors of unstructured antiretroviral treatment interruption and resumption among HIV-positive individuals in Canada. HIV Med. 2015;16(2):76-87.

40. Chesney MA, Ickovics JR, Chambers DB, Gifford AL, Neidig J, Zwickl B, Wu AW. Self-reported adherence to antiretroviral medications among participants in HIV clinical trials: The AACTG adherence instruments. Patient Care Committee \& Adherence Working Group of the Outcomes Committee of the Adult AIDS Clinical Trials Group (AACTG). AIDS Care. 2000;12(3):255-66.
41. Katz IT, Essien T, Marinda ET, Gray GE, Bangsberg DR, Martinson NA, De Bruyn G. Antiretroviral therapy refusal among newly diagnosed HIV-infected adults. AIDS. 2011;25(17):2177-81.

42. Lima VD, Reuter A, Harrigan PR, Lourenço L, Chau W, Hull M, Mackenzie L Guillemi S, Hogg RS, Barrios R, Montaner JSG. Initiation of antiretroviral therapy at high CD4+ cell counts is associated with positive treatment outcomes. AIDS. 2015;29(14):1871-82.

43. World Health Organization. Guidelines on when to start antiretroviral therapy and on pre-exposure prophylaxis for HIV. 2015.

44. Eastwood EA, Birnbaum JM. Physical and sexual abuse and unstable housing among adolescents with HIV. AIDS Behav. 2007;11(2):116-27.

45. Beyrer C, Sullivan PS, Sanchez J, Dowdy D, Altman D, Trapence G, Collins C, Katabira E, Kazatchkine M, Sidibe M, Mayer KH. A call to action for comprehensive HIV services for men who have sex with men. Lancet. 2012;380:424-38.

46. Wohl AR, Garland WH, Wu J, Au CW, Boger A, Dierst-Davies R, Carter J, Carpio F, Jordan W. A youth-focused case management intervention to engage and retain young gay men of color in HIV care. AIDS Care. 2011:23(8):988-97.

47. Wilton J, Broeckaert L. The HIV treatment cascade: Patching the leaks to improve HIV prevention. Toronto CATIE; 2103. http//www.catie.ca/en/pif/spring-2013/hivtreatment-cascade-patching-leaks-improve-hiv-prevention

48. Parashar S, Palmer AK, O'Brien N, Chan K, Shen A, Coulter S, Montaner JS, Hogg RS. Sticking to it: the effect of maximally assisted therapy on antiretroviral treatment adherence among individuals living with HIV who are unstably housed. AIDS Behav. 2011;15(8):1612-22.

49. Krusi A, Small W, Wood E, Kerr T. An integrated supervised injecting program within a care facility for HIV-positive individuals: A qualitative evaluation. AIDS Care. 2009;21:638-44.

50. Spire B, Lucas GM, Carrieri MP. Adherence to HIV treatment among IDUs and the role of opioid substitution treatment (OST). Int J Drug Policy. 2007;18:262-70.

51. Public Health Agency of Canada. HIV and AIDS in Canada: Surveillance Report to December 31, 2013. 2014. p. 140175.

\section{Submit your next manuscript to BioMed Central and we will help you at every step:}

- We accept pre-submission inquiries

- Our selector tool helps you to find the most relevant journal

- We provide round the clock customer support

- Convenient online submission

- Thorough peer review

- Inclusion in PubMed and all major indexing services

- Maximum visibility for your research

Submit your manuscript at www.biomedcentral.com/submit
Biomed Central 